\title{
THE INHERITANCE AND BEHAVIOUR OF THE RAYED GENE COMPLEX IN SENECIO VULGARIS
}

\author{
A. J. RICHARDS \\ Department of Plant Biology, University of Newcastle upon Tyne
}

Received 16.v.74

\begin{abstract}
SUMMARY
Plants of Senecio vulgaris homozygous for the rayed gene $(R R)$ show markedly slower growth characteristics than unrayed plants $(r r)$ from the same British population; the former are, however, very similar in growth to an unrayed population from a Mediterranean district of Yugoslavia (YY). Studies of genetic interaction with $r$, of plasticity, and of taxonomic characters suggest that slow growth has arisen independently in RR and YY. It seems that the rayed allele $R$ is part of a linked gene complex, and it is suggested that this has resulted from introgression with the related Mediterranean species $S$. squalidus, which is now widespread in Britain.

Although it seems likely that RR and $Y Y$ are functionally annual, perhaps in response to the hot summer Mediterranean rest-period experienced by $Y Y$ and native $S$. squalidus, $\mathrm{R}$ may be able to coexist with the more rapidly reproducing $\mathrm{rr}$ genotype in Britain through a superior reproductive capacity in competitive situations.

Considerable variation is noted in the ligule length in the $R r$ heterozygote, in which $R$ is incompletely dominant, and it is suggested that although the artificial selection for dominance in this attribute might be readily demonstrated, there is little evidence of selective pressures leading to dominance in the wild. Indeed a stable polymorphism for $R$ and $r$ seems to exist at the present time.
\end{abstract}

\section{INTRODUCTION}

Senecio vulgaris L., the Groundsel, is an abundant short-lived weed of open ground in the British Isles. It is a member of the Compositae, and the type, and the majority of British populations, bear only tubular florets. At least two variants are known in which the marginal florets are rayed, bearing ligules. These are a maritime ecodeme, subsp. denticulatus (O. F. Muell.) P. D. Sell, which does not concern us here, and a variant, apparently otherwise indistinguishable from inland unrayed plants and occurring in polymorphic populations with them, known as forma ligulatus D. E. Allen (Perring and Sell, 1968).

Trow (1912) first showed that the latter rayed form is controlled by a single major gene, designated $R$ (rayed) and $r$ (unrayed), and that the heterozygote $R r$ produces ray-florets shorter than those in $R R$, there being incomplete dominance. (Hull (1974) has termed these alleles $T r$ and $T n$, which in this case of incomplete dominance may be more correct. However, I prefer to maintain Trow's terminology.) The rare condition of incomplete dominance, in conjunction with the rapid germination, easy growth and short generation time exhibited in this species, render it particularly suitable for various experiments in population genetics. However, although this polymorphism is frequently used for class work, the only published population data I can trace are in Hull (1974). 
The present work shows that the $R$ allele in $S$. vulgaris is associated with a number of slow growth characteristics, which are similar to those in a Mediterranean race of unrayed $S$. vulgaris, but which differ in interactions with British $r r$ plants. It is suggested that these are inherited together with the $R$ allele from the slow-growing winter annual or perennial $S$. squalidus. Preliminary results demonstrate how $R S$. vulgaris may be able to compete with $r r$ plants.

\section{MATERIALS AND METHODS}

Seed was collected from $50 R R$ and $50 \mathrm{rr}$ plants in the vicinity of the Department of Botany, University of Durham, in November 1972, and was bulked and mixed for each type. Seed was also bulked and mixed from a population of unrayed $S$. vulgaris growing in a calcareous cabbage field at Caltet, south Yugoslavia, collected by Dr A. W. Davison in April 1972, this latter being designated $\mathrm{YY}$. In this paper the symbols $\mathrm{R}, \mathrm{r}$ and $\mathrm{Y}$ refer to genomes, $\mathrm{R}$ and $\mathrm{r}$ being associated with the alleles $R$ and $r$ respectively; the corresponding allele in $\mathrm{Y}$ is of $r$ type.

Seed was sown in plastic trays filled to $4 \mathrm{~cm}$ with John Innes No. 3 compost at a density of 1 to $50 \mathrm{~cm}^{2}$, unless otherwise stated. The trays were watered daily, drainage being provided by holes burnt into the tray bottoms. Genotype populations were kept separate unless otherwise stated. The trays were kept in a growth chamber at about $20^{\circ} \mathrm{C}$ with a constant illumination of 900 lux. Germination, growth characters, flowering and leaf characters were measured on all plants at regular intervals. Crosses were made by rubbing heads together at a stage before the stigma branches recoiled, about 2-3 hours following anthesis. Offspring were grown and measured on the assumption that all were hybrids, but at flowering in the second generation, the radiate marker gene enabled non-hybrid offspring to be discounted from calculations. Approximately 50 per cent of crossed seed were in fact hybrid.

Preliminary experiments on competition and the effect of density were performed on a latin array in conditions as above.

\section{EXPERIMENTS}

(i) Variation in ray length in heterozygous $\mathrm{Rr}$ and homozygous $\mathrm{RR}$ plants

All ray-florets were removed from $20 \mathrm{Rr}$ and $10 \mathrm{RR}$ plants, giving a sample of not less than 50 florets per plant. These were carefully mounted to their full length on " sellotape " and measured at $\times 40$ using a compound microscope with an eye-piece graticule, previously calibrated to $\mathrm{mm}$. The $\mathrm{RR}$ homozygotes all possessed rays longer than heterozygotes, and showed relatively small variation in mean measurement, $7 / 10$ averaging between $8 \cdot 0$ and $9.0 \mathrm{~mm}$. In contrast, the heterozygotes $\mathrm{Rr}$ varied between 2.0 and 7.0 $\mathrm{mm}$ in mean length, and in view of the small standard deviations involved $(0 \cdot 1-0 \cdot 8)$, the large samples of rays from different capitula and the standard growth conditions, it may be reasonably assumed that at least some of this variation in ray length is under genetic control. It is probable that artificial selection of heterozygotes resulting from selfing extreme $\mathrm{Rr}$ forms would lead to the expression of complete dominance, as has been shown, for instance, by Ford (1940). Nevertheless it is clear that, at least in the Durham population, 
a variable incomplete dominance occurs, suggesting in view of the large population size (usually in excess of 3000) and the high frequency of the $R$ allele (7-30 per cent) that there is little selective advantage for $R$ or $r$.

\section{(ii) Germination}

Germination was recorded over a period of 83 days from sowing. No germination occurred during the first 11 days. Final germination represented from 35 to 91 per cent of the seeds sown. Popay and Roberts (1970) have shown that Senecio vulgaris has a light requirement for germination, which can be overcome to a certain extent by cold treatment, and that winter seed shows some dormancy. As both $\mathrm{R}$ and $\mathrm{r}$ seed was collected during the winter and seed, covered by soil, was not subjected to pregermination temperature shocks (being maintained at about $20^{\circ} \mathrm{C}$ prior to and during germination) it may be presumed that incomplete germination may be attributable to these factors. However, the considerable differences displayed in time to germination and rate of germination in the samples (table 1) may be at least

TABLE 1

Germination of seed

$\begin{array}{cccc}\text { Genotype } & \begin{array}{c}\text { Time to initial } \\ \text { germination } \\ \text { (days) }\end{array} & \begin{array}{c}\text { Time to final } \\ \text { germination } \\ \text { (days) }\end{array} & \begin{array}{c}\text { Percentage of } \\ \text { total germination }\end{array} \\ \text { rr } & 11 & 22 & 90 \\ \text { Rr } & 15 & 67 & 47 \\ \text { RR } & 12 & 47 & 35 \\ \text { Yr } & 12 & 59 & 68 \\ \text { YY } & 20 & 53 & 91 \\ \text { YR } & 20 & 67 & 40\end{array}$

Note.-Although homozygote seed was genotypically pure, seed of supposed heterozygotes later proved to be up to 50 per cent homozygous.

partly due to genetic differences. Of the homozygotes, rr showed a much more rapid and synchronised germination, 80 per cent of seedlings appearing inside 5 days. The slower rates of germination in RR and $Y Y$ were similar. However, although RR germinated rather earlier than $Y Y$, the final germination was much lower. Of the heterozygotes, $\mathrm{Rr}$ and $\mathrm{YR}$ showed patterns not dissimilar to, although rather slower than RR and YY. Yr showed a rapid initial germination typical of one parent ( $r r$ ) and a slower subsequent germination, more typical of the other parent YY.

\section{(iii) Growth}

Rates of growth were established by three criteria:

(a) height (maximum length of plant from soil to apical bud);

(b) number of leaves (excluding cotyledons, but including dead leaves and leaf-scars);

(c) time to flower (anthesis of first capitulum on plant).

It was not possible to determine dry weights due to limitations on growth space. 
Height (table 2). rr plants showed a quicker initial growth phase than the other homozygotes and reached a flowering condition in about 20 days from germination, after which growth became very much slower. The much slower growth rates of $\mathrm{RR}$ and $\mathrm{YY}$ were indistinguishable. $\mathrm{Yr}$ plants behaved in a similar manner to $\mathrm{rr}$ while $\mathrm{Rr}$ heterozygotes initially behaved as the RR parent, but latterly grew more slowly than either parent.

\begin{tabular}{|c|c|c|c|c|c|c|c|c|c|}
\hline \multirow[b]{2}{*}{ Genotype } & \multicolumn{9}{|c|}{$\begin{array}{c}\text { TABLE } 2 \\
\text { Plant height }(\mathrm{mm})\end{array}$} \\
\hline & 5 & 10 & 15 & 20 & 25 & 30 & 35 & 40 & 45 \\
\hline $\begin{array}{l}\mathrm{rr} \\
\mathrm{Rr}\end{array}$ & $\begin{array}{l}28 \pm 4 \\
10 \pm 1\end{array}$ & $\begin{array}{l}42 \pm 6 \\
15 \pm 1\end{array}$ & $\begin{array}{l}49 \pm 5 \\
17 \pm 1\end{array}$ & $\begin{array}{l}55 \pm 7 \\
19 \pm 1.5\end{array}$ & $-\overline{26 \pm 6}$ & $\begin{array}{l}56 \pm 9 \\
25 \pm 4\end{array}$ & - & $\overline{27 \pm 5}$ & - \\
\hline $\mathrm{RR}$ & $13 \pm 1$ & $16 \pm 1$ & $22 \pm 2$ & $27 \pm 5$ & $32 \pm 5$ & 二 & $45 \pm 11$ & - & $51 \pm 19$ \\
\hline $\mathrm{Yr}$ & $28 \pm 3$ & $37 \pm 4$ & - & $55 \pm 6$ & $=$ & $53 \pm 3$ & - & - & 二 \\
\hline$Y Y$ & $12 \pm 0.5$ & $13 \pm 1$ & $16 \pm 1$ & $23 \pm 1 \cdot 5$ & $27 \pm 2$ & $27 \pm 1.5$ & $40 \pm 3$ & - & $57 \pm 17$ \\
\hline
\end{tabular}

Number of leaves (table 3). rr plants developed leaves more quickly than the other homozygotes, and reached a maximum number of leaves at about 20 days from germination, at which point flowering commenced. The slower rate of leaf development of RR and YY are scarcely distinguishable although there is an indication that RR may develop leaves slightly more quickly. Yr plants were indistinguishable from $\mathrm{rr}$ while $\mathrm{Rr}$ plants could not be differentiated from the RR parent.

TABLE 3

Number of leaves

Days from germination

\begin{tabular}{|c|c|c|c|c|c|c|c|}
\hline Genotype & 5 & 10 & 15 & 20 & 25 & 30 & 35 \\
\hline $\mathrm{rr}$ & $5 \cdot 5 \pm 0.8$ & $7 \cdot 1 \pm 0 \cdot 1$ & - & $10 \cdot 6 \pm 1 \cdot 4$ & - & $10 \cdot 1 \pm 1 \cdot 0$ & - \\
\hline $\mathrm{Rr}$ & $1.9 \pm 0.3$ & $3.9 \pm 0.7$ & $3.9 \pm 0.5$ & $6 \cdot 1 \pm 0 \cdot 6$ & $7 \cdot 6 \pm 1 \cdot 2$ & \pm & $10 \cdot 6 \pm 0 \cdot 1$ \\
\hline $\mathrm{RR}$ & $2 \cdot 4 \pm 0.6$ & - & $3.4 \pm 0.9$ & $6 \cdot 2 \pm 1 \cdot 0$ & $6 \cdot 3 \pm 1 \cdot 9$ & - & $9 \cdot 2 \pm 3 \cdot 1$ \\
\hline $\mathrm{Yr}$ & $4 \cdot 3 \pm 1 \cdot 2$ & $5.8 \pm 1.9$ & $9 \cdot 3 \pm 1 \cdot 7$ & $9 \cdot 5 \pm 1.2$ & - & $12 \cdot 1 \pm 1 \cdot 6$ & 二 \\
\hline$Y Y$ & $1.4 \pm 0.3$ & $2 \cdot 0 \pm 0 \cdot 2$ & $2 \cdot 6 \pm 0 \cdot 2$ & $3.8 \pm 0.3$ & $5 \cdot 3 \pm 0.5$ & $5 \cdot 5 \pm 0.8$ & $7 \cdot 2 \pm 0.9$ \\
\hline
\end{tabular}

Time to flowering (table 4). A substantial proportion of all plants failed to flower during the 90 days of the experiment. This may have been due to the low density at which they were planted. Nevertheless, although rr plants commenced flowering only 18 days after germination, and by 30 days 63 per cent of plants were in flower (no more flowered subsequently), the performance of the other strains was much poorer. $\mathrm{YY}$ and $\mathrm{Rr}$ plants did not commence flowering until 48 days had elapsed from germination, and when the experiment was brought to an end due to a departmental move, only 12 and 15 per cent respectively had commenced flowering. These and the heterozygote $\mathrm{Rr}$ were indistinguishable in their behaviour. Conversely, the heterozygote Yr was intermediate in its behaviour between its parents $\mathrm{YY}$ and $\mathrm{rr}$.

In summary, in all growth characteristics measured, the British irradiate strain $\mathrm{rr}$ showed strikingly faster germination and development than either 
the Yugoslavian irradiate strain, or the British radiate form. The latter two strains, of very different origins, were inseparable on all attributes measured.

TABLE 4

Time to flowering. Percentage of living plants to have flowered

Days from germination

$\begin{array}{lrrrrrrrrrrr}\text { Genotype } & 5 & 10 & 15 & 20 & 25 & 30 & 35 & 40 & 45 & 50 & 55 \\ \mathrm{rr} & 0 & 0 & 0 & 29 & 52 & 63 & 63 & 63 & 63 & 63 & 63 \\ \mathrm{Rr} & 0 & 0 & 0 & 0 & 0 & 0 & 0 & 0 & 10 & 13 & 15 \\ \mathrm{RR} & 0 & 0 & 0 & 0 & 0 & 0 & 0 & 0 & 0 & 10 & 10 \\ \mathrm{Yr} & 0 & 0 & 0 & 0 & 6 & 16 & 29 & 39 & 46 & 46 & 46 \\ \mathrm{YY} & 0 & 0 & 0 & 0 & 0 & 0 & 0 & 0 & 0 & 0 & 12\end{array}$

\section{(iv) Leaf length (table 5)}

This attribute is being considered separately from the growth characteristics partly because leaves fairly rapidly reach their maximum length and thus the developmental capability of an organ is being considered, rather than its rate of growth, and partly because the results show a pattern of control and interaction different from those of growth characteristics. The length from apex to petiole base of the longest leaf, at its full extension, was measured for each plant.

TABLE 5

Leaf length (mm)

Days from germination

$\begin{array}{ccccccc}\text { Genotype } & 5 & 10 & 15 & 20 & 25 & 30 \\ \mathrm{rr} & 30 \pm 3 & 39 \pm 5 & 43 \pm 7 & 54 \pm 4 & - & - \\ \mathrm{Rr} & 18 \pm 4 & 17 \pm 1 \cdot 4 & 20 \pm 2 & - & 21 \pm 3 & 29 \pm 8 \\ \mathrm{RR} & 21 \pm 2 & 25 \pm 7 & 28 \pm 7 & - & 37 \pm 10 & - \\ \mathrm{Yr} & 32 \pm 4 & 35 \pm 3 & 36 \pm 11 & 45 \pm 9 & - & 41 \pm 11 \\ \mathrm{YY} & 23 \pm 5 & 34 \pm 10 & 35 \pm 8 & 50 \pm 13 & - & -\end{array}$

Although the homozygotes $\mathrm{rr}$ and $\mathrm{RR}$ are more or less separable, $\mathrm{rr}$ plants having longer leaves, the Yugoslavian non-rayed strain is intermediate between the two and is statistically inseparable from either. This contrasts markedly with the growth characteristics in which the rr strain was invariably separable from the other two, which could not be distinguished.

The heterozygote Yr was inseparable from its parents $\mathrm{YY}$ and $\mathrm{rr}$, but $\mathrm{Rr}$ heterozygotes showed smaller leaves than either parent.

\section{(v) Plasticity}

Although the experiments reported so far were performed at the same time, in standard conditions, and using the same soil source, initial experiments of a similar nature were made a generation previously on the homozygous strains rr, RR and YY. Indeed it was from these that the crosses giving rise to the heterozygotes were made. Although the initial experiments (generation 1) were subject to the same heating and lighting conditions as generation 2, the results differ in several important respects. This may well be due to the soil, which although made up as John Innes No. 3 on both 
occasions, probably differed in the loam constituent, particularly with regard to $\mathrm{N}, \mathrm{P}$ and $\mathrm{K}$. Whatever the cause it can be assumed, that an important environmental difference occurred between generations 1 and 2 (table 6).

TABLE 6

Effect of different soil types (plasticity)

Genotype and generation

rr (Gen. 1)

rr (Gen. 2)

RR (Gen. 1)

RR (Gen. 2)

YY (Gen. 1)

YY (Gen. 2)

rr (Gen. 1)

rr (Gen. 2)

RR (Gen. 1)

RR (Gen. 2)

YY (Gen. 1)

YY (Gen. 2)
Days from germination

\begin{tabular}{rrrllllll}
\hline 5 & 10 & 15 & 20 & 25 & 30 & 35 & 40 & 45 \\
32 & 50 & 76 & - & - & - & - & - & - \\
28 & 42 & 49 & 55 & - & 56 & - & - & - \\
4 & 7 & 9 & 17 & 25 & - & - & - & - \\
13 & 16 & 22 & 27 & 32 & - & 45 & - & 51 \\
9 & 13 & 19 & 40 & 62 & - & - & - & - \\
12 & 13 & 16 & 23 & 27 & 27 & 40 & - & 57 \\
4 & 21 & 26 & 30 & - & - & & & \\
30 & 39 & 43 & 54 & - & - & & & \\
7 & 20 & 32 & - & - & - & & & \\
21 & 25 & 28 & - & 37 & - & & & \\
7 & 19 & 36 & - & - & - & &
\end{tabular}

Although the samples were in each case genetically comparable, striking differences occurred between strains in some characteristics. The comparability of other attributes strongly suggests that some characteristics are subject to much greater plasticity (genotype-environment interaction) than others. Thus, in height, the later stages of growth are much enhanced in generation 1 for $\mathrm{rr}$ and $\mathrm{YY}$, although the corresponding results for the two generations of RR are much more comparable. This suggests that the two non-rayed strains have a high capacity for plasticity in this attribute, while that of RR is minimal. Similarly, in leaf length the two generations of $\mathrm{rr}$ differ strikingly, although there is no discernible difference in this attribute for either YY or RR.

\section{(vi) Dominance}

It is of interest to consider the behaviour of heterozygotes with respect to their parents (table 7). To summarise, in growth characteristics, $R$ is

TABLE 7

Gene interactions

\begin{tabular}{|c|c|c|c|c|c|c|}
\hline $\mathrm{r}$ with others & $\begin{array}{c}\mathbf{Y} \\
\text { dominant }\end{array}$ & $\begin{array}{c}\mathbf{F}_{\mathbf{1}} \\
\text { inter- } \\
\text { mediate }\end{array}$ & $\underset{\text { dominant }}{r}$ & $\underset{\text { dominant }}{R}$ & $\begin{array}{c}\mathrm{F}_{1} \\
\text { inter- } \\
\text { mediate }\end{array}$ & $\begin{array}{c}r \\
\text { dominant }\end{array}$ \\
\hline Germination & - & + & - & + & - & - \\
\hline Time to flower & - & + & - & + & - & - \\
\hline Height & - & - & + & + & - & - \\
\hline Leaf number & - & - & + & + & - & - \\
\hline Leaf length & - & - & - & - & + & - \\
\hline Ligule & - & - & - & - & + & - \\
\hline
\end{tabular}

always dominant to $\mathrm{r}$, while $\mathrm{r}$ is either dominant to $\mathrm{Y}$, or there is an intermediate effect. There is thus strong evidence that growth characteristics 
are heritable, and that the two slow-growing forms, RR and $\mathrm{YY}$ are of quite distinct type, behaving totally differently when combined with $r$, suggesting that each has a quite different genetic background. There is no indication of heterozygote advantage or heterosis; indeed, heterozygotes frequently perform less well than either of their homozygote parents. In contrast, in non-growth characteristics (leaf-length and ligule), heterozygotes $\mathrm{Rr}$ are intermediate between the parents $R R$ and $r r$, rather than showing full $R$ dominance.

\section{(vii) Generation time}

It is clear that rr plants differ from RR and YY plants in showing quicker germination, growth and flowering. The cumulative effect of this is summarised in table 8. To make data comparable, the time to complete germination

TABLE 8

Generation time (days) (15 days added to account for time to seed-set)

$\begin{array}{lccc}\text { Strain } & \begin{array}{c}\text { time to } \\ \text { complete germination }\end{array} & \begin{array}{c}\text { time to } \\ \text { first flower }\end{array} & \text { Total } \\ \text { rr } & 37 & 18 & 70 \\ \text { RR } & 61 & 47 & 123 \\ \text { YY } & 67 & 47 & 129 \\ \text { Yr } & 75 & 24 & 114 \\ \text { Rr } & 83 & 42 & 141\end{array}$

is added to the time of appearance of first flower. No data is available on the time from anthesis to seed dispersal in the first flowering capitulum, and it is assumed that this figure does not vary between strains. It is estimated as about 15 days. Generation time in the conditions of generation 2 was thus about 70 days for rr, but nearly twice as long for RR and YY, which at 123 and 129 days showed no important difference, despite the very different origin of the populations, and the apparently different nature of the genetic control, as shown by interaction with $r$. The heterozygote $\mathrm{Yr}$ had a slightly quicker generation time than $\mathrm{YY}$, at 114 days, but that of $\mathrm{Rr}$ was depressed below either parent, at 141 days. It should be noted here that generation time is largely dependent on external conditions. Haskell (1953) records generation times from 57 to 123 days from the same family, depending on date of sowing.

These figures suggest, in view of the relatively favourable growth conditions to which the plants were subjected, that although rr plants might readily achieve 3 or 4 generations in a year, $R R, R r$ and $Y Y$ plants would be unlikely to have more than 2 generations annually. Indeed, in many conditions, such as the hot, dry summer which the Yugoslavian YY plants are accustomed, they may only achieve one generation per year.

\section{(viii) Reproductive potential}

We may assume that the Yugoslavian population YY shows growth characteristics which adapt it to growth during the cool wet Mediterranean winter, and that it is dormant during the hot dry summer. It is thus unlikely that there is any question of competition with genotypes showing different growth attributes. However, the $\mathrm{R}$ and $\mathrm{r}$ genotypes, which differ approximately by a factor of two in their generation time, are polymorphic in the 
same population. The question thus arises as to how the $\mathrm{R}$ genotype, with a long generation time is able to compete with the faster growing $\mathrm{r}$ morph. Observation suggests that the two morphs show no habitat difference in the Durham population, and that $R R, R r$ and $r r$ morphs frequently grew together in very dense stands. Some initial data from a competition experiment at the high density of 1 plant $/ 4 \mathrm{~cm}^{2}$ (table 9) suggests that, in competitive

TABLE 9

Reproductive potential ( 1 plant $/ \mathrm{cm}^{2}$ )

\begin{tabular}{lrr} 
& $R R$ & \multicolumn{1}{c}{$r r$} \\
$\overline{\mathrm{x}}$ no. seeds/capitulum & 23 & 20 \\
$\mathrm{x}$ no. capitula/plant & 6 & 1 \\
$\overline{\mathrm{x}}$ no. seeds/plant & 138 & 20
\end{tabular}

situations, $R R$ is able to develop as many as 6 times as many capitula as $r r$, and has a seed output of about 7 times as much. If this experimental result is repeatable at this and other densities, it may explain how $R R$ plants are able to become established in a $r r$ population, despite their slower generation time. It should be noted that Haskell (1953) records a much higher output per $r$ plant (about 100 seeds), but in these it is presumed that intraspecific competition was low. He further suggests that $R R$ plants might have a lower seed output by virtue of the radiate florets, but offers no data to support this.

\section{Discussion}

It is found that rayed morphs $R R$ and $R r$ occurring in a British population of unrayed $S$. vulgaris $(r r)$ show a markedly slower rate of germination, growth, development and time to flowering. In these attributes, $R R$ plants closely resemble a Mediterranean race of unrayed $S$. vulgaris (YY). However, the $R$-associated genome, $\mathrm{R}$, affects growth in a quite different manner from $\mathrm{Y}$ when associated with $\mathrm{rr}$ in $\mathrm{F}_{1}$ hybrids. Furthermore, in the taxonomic character of ligule absence, and of leaf-length, $Y$ plants behave similarly to $r$. There is no indication of heterosis in $F_{1}$ types as recorded by Trow (1912) and suggested by Haskell (1953).

The origin of the $R$ allele in $S$. vulgaris is not certain, but there is circumstantial evidence that it arose from introgression with the introduced $S$. squalidus L., a native of South Italy and Sicily, although $S$. vulgaris is tetraploid $(2 n=40)$ and $S$. squalidus diploid $(2 n=20)$.* Rayed plants were not recorded inland in Britain before 1870, and as it is a striking variant of a familiar species, and considering the Victorian propensity for describing minor variants, it is reasonable to assume that it did not occur. Inland rayed morphs had been described in Germany in 1843, but there is no evidence that these are of a similar nature. Certainly $R$ morphs were scarce in Britain well into the twentieth century, and many local floras since 1930 have remarked on the increase and spread of these morphs latterly. The map in Perring and Sell (1968) shows that they are now widespread in England and Wales. There is a striking similarity with the map of

* Haskell (1953) considers $S$. vulgaris to be an octoploid, Senecio having a base-number of $x=5$. As only 2 of 232 specific counts reported in Federova (1969) are $2 n=10$, this seems a tenuous view. 
S. squalidus (Perring and Walters, 1962), superficially a very different species.

S. squalidus was first recorded adventive in Britain in 1794, in Oxford, where it had been introduced at the Botanic Garden. It was not until Oxford was linked to a railway system that it was recorded outside Oxford, and prior to 1900 it was still extremely local (Perring and Walters, 1962). Since then it has become very much more widespread and abundant and is now a familiar weed in most parts of England and Wales.

As early as 1886 , Druce had recorded $R$ morphs of $S$. vulgaris in company with $S$. squalidus and hybrids with unrayed $S$. vulgaris. Such populations are now commonplace, although they have rarely been recorded in the literature. I know of such populations next to the Botany Departments of Manchester, Oxford, Durham and Keele Universities, and in the cities of Newcastle and Derby. Plants which are apparently $F_{1}$ hybrids are uncommon, and are usually seed-sterile. However, G. G. Vosa (pers. comm.) has observed some seed set in a presumed $F_{1}$ hybrid in the grounds of the Botany School, Oxford, and comments that $R$ morphs in $S$. vulgaris had not occurred previous to the detection of hybrids. They are now common there. I have received several other verbal communications that $R$ morphs in $S$. vulgaris only appeared after the arrival locally of $S$. squalidus, but many echo Allen (1967) that hybrids are sterile. A comparison of historical and geographical evidence strongly suggests that enough fertility may occur in the $F_{1}$ to allow the origin of more fertile backcross types of $S$. vulgaris. Although Crisp (pers. comm.) has been unable to repeat this experimentally, he records the origin of many tetraploid offspring $(2 n=40)$ from an apparently hybrid plant. Some of these resembled rayed $S$. vulgaris (Crisp and Jones, 1970).

Certainly it would seem that the $R$ allele is likely to have originated in a rayed species with slow growth characteristics similar to a Mediterranean race of $S$. vulgaris, and thus perhaps from that area. $S$. squalidus fits this description, and there is considerable circumstantial evidence of a historical and geographical nature that S. squalidus is indeed the other parent. Although little is known about the separate genetic control of the attributes investigated, they seem to be inherited together, and in association with the rayed factor. There would therefore seem to be a linkage group involved, perhaps a whole chromosome, probably inherited from $S$. squalidus and now occurring polymorphically in many $S$. vulgaris populations. There is no evidence of recombinant types, and there may well exist a selection pressure to keep the various $R$ attributes associated. Alternatively, the gene complex may be closely linked, resulting only rarely in recombination inside the complex, or all the $R$ attributes could be pleiotropic expressions of a single major gene. The latter explanation has been advanced by Haskell (1953) who further suggests that such pleiotropic expressions of $R$ morphs might serve to limit the spread of $R$ morphs, which he considers aboriginal. I can see no justification for either of his views. Work is proceeding in the search for recombinants, and if they are discovered, their survival potential will be assessed through competition experiments.

Acknowledgment.-I should like to thank Mrs J. Wobey for help with data on ligule length and competitive performance, and V. A. Williams for providing the data on the first generation and making the experimental crosses. 


\section{REFERENCES}

ALLEN, D. E. 1967. Taxonomy and nomenclature of the radiate variants Senecio vulgaris $L$. Watsonia, 6 (5), 280-282.

CRISP, P., AND JONES, B. M. G. 1970. Senecio squalidus L., S. vulgaris L. and S. cambrensis Rosser. Watsonia, 8, 47-48.

DRUCE, G. c. 1886. Flora of Oxfordshire. Oxford.

Federova, A. A. 1969. Chromosome Numbers of Flowering Plants. V. L. Komerov Botanical Institute, Leningrad.

FORD, E. B. 1940. Genetic research in the Lepidoptera. Ann. Eugen., Lond., 10, 227-252. HASKELL, G. 1953. Adaptation and the breeding system of groundsel. Genetica, 26, 468-484. HULL, P. 1974. Self-fertilisation and the distribution of the radiate form of Senecio vulgaris L. in Central Scotland. Watsonia, 10, 69-75.

PERring, R. H., AND SELl, P. D. 1968. Critical Supplement to the Atlas of the British Flora. London.

PERRING, R. H. AND WAlters, s. M. 1962. Atlas of the British Flora. London.

POPAY, A. I., AND ROBERTS, E. H. 1970. Factors involved in the dormancy and germination of Capsella bursa-pastoris (L.) Medic. and Senecio vulgaris L. J. Ecol., 58, 103-122.

Trow, A. H. 1912. On the inheritance of certain characters of the common groundsel. 7. Genet., 2, 239. 